\title{
Through rose-colored glasses: Bringing focus back to revascularization
}

\author{
Dawn S. Hui, MD, and Richard Lee, MD, MBA
}

\author{
From the Center for Comprehensive Cardiovascular Care, Saint Louis University, St Louis, Mo. \\ Disclosures: Authors have nothing to disclose with regard to commercial support. \\ Received for publication Oct 2, 2016; revisions received Oct 2, 2016; accepted for publication Oct 4, 2016; \\ available ahead of print Nov 19, 2016. \\ Address for reprints: Richard Lee, MD, MBA, Center for Comprehensive Cardiovascular Care, 3635 Vista Ave, \\ DT 13F, St Louis, MO 63110 (E-mail: rlee@slu.edu). \\ J Thorac Cardiovasc Surg 2017;153:314-6 \\ $0022-5223 / \$ 36.00$ \\ Copyright (c) 2016 by The American Association for Thoracic Surgery \\ http://dx.doi.org/10.1016/j.jtcvs.2016.10.022
}

In this issue of the Journal, Zheng and colleagues ${ }^{1}$ approach the topic of percutaneous coronary intervention (PCI) for unprotected left main (ULM) disease. As they discuss, previous studies of revascularization strategies for ULM disease have demonstrated comparable mortality or composite outcomes with PCI and coronary artery bypass grafting (CABG). Accordingly, European Society of Cardiology and European Association for Cardio-Thoracic Surgery guidelines for PCI in ULM disease have changed to class I. From their comments, one might be led to believe that change for the North American guidelines is inevitable.

On the basis of their own institutional study, ${ }^{2}$ Zheng and colleagues conclude that "PCI is a reasonable alternative treatment to $\mathrm{CABG}$ ", for less complex left main disease. Briefly, their findings were as follows: comparatively, there was a higher mortality with PCI $(3.8 \%$ vs $2.5 \%)$ that was significant. Subgroup analysis showed a survival benefit of CABG in those with more complex disease (Synergy Between Coronary Intervention with TAXUS and Cardiac Surgery [SYNTAX] score $\geq 33$ ), left ventricular ejection fraction less than 50\%, ULM bifurcation, and euroSCORE no greater than 1; otherwise, patients with SYNTAX score less than 33 had equivalent mortalities with the two revascularization strategies.

Although the strengths of the article of Zheng and colleagues $^{1}$ ( size of $n=4046 ;>90 \%$ follow-up at 3 years; and contemporary practices such as exclusive use of drug-eluting stents, heart team approach, and guidelinedirected optimal medical therapy [OMT]) are notable, the biases and weaknesses of an observational study are not insignificant. First, the groups were quite unbalanced, with the patients with $\mathrm{CABG}$ significantly older, more often women, and more often possessing all studied risk factors (other than chronic obstructive pulmonary disease), cardiovascular comorbidities (other than peripheral vascular disease), 3-vessel rather than 2-vessel disease, and higher euroSCORE and SYNTAX scores. Sophisticated statistical techniques were used to adjust for selection bias and potential confounding, but one wonders

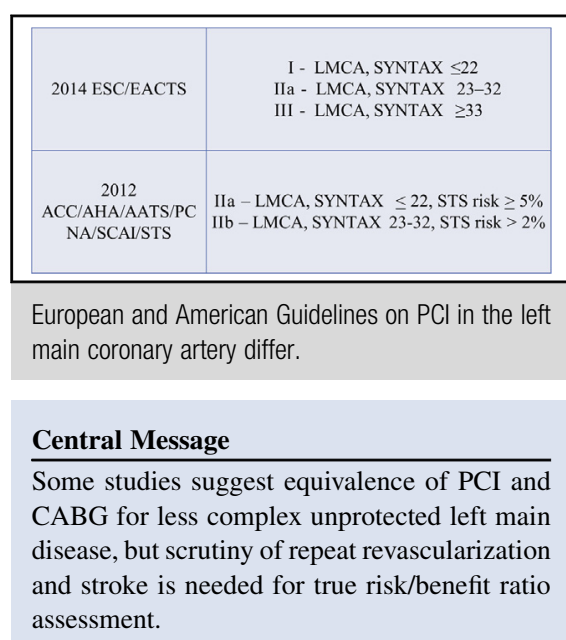

See Article page 312

whether such methodology is a bit of sleight of hand that can truly correct for the numerous between-group differences.

Second, although Zheng and colleagues ${ }^{1}$ mention use of current pharmacologic treatment practices, the actual adoption of OMT was not quantified. In the SYNTAX study, OMT reduced 5-year mortality (36\% relative reduction) and the composite of death, myocardial infarction, and stroke, regardless of revascularization strategy. ${ }^{3}$ Significantly, OMT use was higher in the PCI group than in the CABG group at discharge $(50.2 \%$ vs $31.2 \%)$, and low in both groups at 5 years. Factors leading to unequal adoption in the SYNTAX study may well have been in play with this group as well. Third, SYNTAX scores were missing in nearly one-third of their cohort. Finally, as Zheng and colleagues acknowledge, subgroup analyses were underpowered and "should be regarded as hypothesis generating only.", 2

While awaiting the results of the Evaluation of the Xience Everolimus Eluting Stent Versus Coronary Artery Bypass Surgery for Effectiveness of Left Main Revascularization (EXCEL) and Coronary Artery Bypass Grafting Versus Drug Eluting Stent Percutaneous Coronary Angioplasty in the Treatment of Unprotected Left Main Stenosis (NOBLE) trials, and if tentatively accepting the hypothesis of equivalent mortality for low-complexity disease, does the evidence support a rosier and rosier view of PCI? As stated by Mack and associates, "in-depth analysis of stroke is crucial to 
TABLE 1. Large registry or randomized studies that support the European Association for Cardio-Thoracic Surgery guidelines

\begin{tabular}{lccc}
\hline \multicolumn{1}{c}{ Study } & Follow-up $(\mathbf{y})$ & Stroke risk, CABG vs PCI $(\%)$ & TVR $($ HR and 95\% CI) \\
\hline Registry studies & & & \\
MAIN-COMPARE $(2010)^{5} ; \mathrm{n}=2240$ & 5.2 & Not reported & $5.11^{*}(3.52-7.42)$ \\
ASAN-MAIN $(2010)^{6} ;$ BMS arm $\mathrm{n}=350$ & 10 & 8.8 vs 5.5 & $10.34^{*}(4.61-23)$ \\
ASAN-MAIN $(2010)^{6} ;$ DES arm $\mathrm{n}=395$ & 5 & 5.9 vs $1.7^{*}$ & $6.22^{*}(2.26-17.14)$ \\
DELTA $(2012)^{7} ; \mathrm{n}=2275$ & 3.5 & 2.9 vs $1.6 \dagger$ & $3.51^{*}(2.4-5.13)$ \\
Randomized trials & & & $2.11^{*}(1.17-3.62)$ \\
PRECOMBAT $(2015)^{8} ; \mathrm{n}=600$ & 5 & 0.7 vs 0.7 & $2.77^{*}(1.17-6.58)$ \\
PRECOMBAT-2 $(2012)^{9} ; \mathrm{n}=334$ & 1.5 & 0.3 vs 0.4 & $1.82^{*}(1.28-2.57)$ \\
SYNTAX $(2014)^{10} ; \mathrm{n}=705$ & 4 & 4.3 vs $1.5^{*}$ & \\
\hline
\end{tabular}

$C A B G$, Coronary artery bypass grafting; $P C I$, percutaneous coronary intervention; $T V R$, target vessel revascularization; $H R$, hazard ratio; $C I$, confidence interval; $M A I N$ COMPARE, Revascularization for Unprotected Left Main Coronary Artery Stenosis: Comparison of Percutaneous Coronary Angioplasty Versus Surgical Revascularization; ASAN-MAIN, ASAN Medical Center-Left Main Revascularization; BMS, bare metal stent; DES, drug-eluting stent; DELTA, Drug Eluting Stents for Left Main Coronary Artery Disease; PRECOMBAT, Premiere of Randomized Comparison of Bypass Surgery Versus Angioplasty Using Sirolimus-Eluting Stent in Patients With Left Main Coronary Artery Disease; SYNTAX, Synergy Between Coronary Intervention with TAXUS and Cardiac Surgery. $* P<.05$. $†$ Significance not reported.

determine the true risk/benefit ratio of PCI and CABG, weighing the risk of stroke versus the risk of repeat revascularization." Zheng and colleagues ${ }^{1}$ state that "numerous studies" report higher risk of stroke with CABG. It is worth spending some time dissecting this assertion. First, the number of large registry or randomized studies that support the European Association for Cardio-Thoracic Surgery guidelines is small (Table 1). Second, only 2 of the 5 studies that reported stroke rates showed statistical significance at late follow-up-the drug-eluting stent arm of the ASAN Medical Center-Left MAIN Revascularization trial ${ }^{6}$ and the SYNTAX trial. ${ }^{11}$ As these stroke rates are higher than perioperative stroke rates, even further investigation is revealing. In the SYNTAX trial, no preprocedural strokes occurred in the PCI arm, whereas 3 patients in the CABG arm had strokes before the index procedure, and 1 of these patients crossed over to the medical therapy arm. ${ }^{4}$ It is unclear whether these patients had left main or 3-vessel disease; however, left main disease is a well-known risk factor for carotid disease, and analysis showed significant stroke risk in the left main, not the 3vessel, subgroup. There remain perioperative and operative opportunities for improving stroke rates, including aggressive screening with computed tomography. ${ }^{12} \mathrm{Sec}-$ ond, although increased stroke after CABG is often attributed to perioperative events, other factors may contribute to long-term risk. Zheng and colleagues ${ }^{1}$ conjecture that a higher predisposition to concomitant cerebrovascular disease may play a role, which is highly possible given the higher comorbidities of their $\mathrm{CABG}$ group. What is clear is that across all trials PCI is associated with significantly higher rates of target vessel revascularization (Table 1).

Although the gap between outcomes for CABG and PCI in ULM disease seems to be narrowing, focused examination of the cumulative evidence for PCI in ULM disease demonstrates that all is not as rosy as it may appear.
We look forward to what the upcoming EXCEL and NOBLE randomized trials will do toward a clearer view of this topic.

\section{References}

1. Zheng Z, Zhang H, Xu B. Updated evidence for left main coronary artery disease practice versus the consensus. J Thorac Cardiovasc Surg. 2017; $153: 312-3$.

2. Zheng Z, Xu B, Zhang H, Guan C, Xian Y, Zhao Y, et al. Coronary artery bypass graft surgery and percutaneous coronary interventions in patients with unprotected left main coronary artery disease. JACC Cardiovasc Interv. 2016;9: $1102-11$.

3. Iqbal J, Zhang YJ, Holmes DR, Morice MC, Mack MJ, Kappetein AP, et al. Optimal medical therapy improves clinical outcomes in patients undergoing revascularization with percutaneous coronary intervention or coronary artery bypass grafting: insights from the Synergy Between Coronary Intervention with TAXUS and Cardiac Surgery (SYNTAX) trial at the 5-year follow-up. Circulation. 2015;131:1269-77.

4. Mack MJ, Head SJ, Holmes DR Jr, Stahle E, Feldman TE, Colombo A, et al. Analysis of stroke occurring in the SYNTAX trial comparing coronary artery bypass surgery and percutaneous coronary intervention in the treatment of complex coronary artery disease. JACC Cardiovasc Interv. 2013;6: 344-54.

5. Park DW, Seung KB, Kim YH, Lee JY, Kim WJ, Kang SJ, et al. Long-term safety and efficacy of stenting versus coronary artery bypass grafting for unprotected left main coronary artery disease: 5-year results from the MAIN-COMPARE (Revascularization for Unprotected Left Main Coronary Artery Stenosis: Comparison of Percutaneous Coronary Angioplasty Versus Surgical Revascularization) registry. J Am Coll Cardiol. 2010;52:117-24.

6. Park DW, Kim YH, Yun SC, Lee JY, Kim WJ, Kang SJ, et al. Long-term outcomes after stenting versus coronary artery bypass grafting for unprotected left main coronary artery disease: 10-year results of bare-metal stents and 5-year results of drug-eluting stents from the ASAN-MAIN (ASAN Medical Center-Left MAIN Revascularization) Registry. J Am Coll Cardiol. 2010;56:1366-75.

7. Chieffo A, Meliga E, Latib A, Park SJ, Onuma Y, Capranzano P, et al. Drugeluting stent for left main coronary artery disease. The DELTA registry: a multicenter registry evaluating percutaneous coronary intervention versus coronary artery bypass grafting for left main treatment. JACC Cardiovasc Interv. 2012;5: 718-27.

8. Ahn JM, Roh JH, Kim YH, Park DW, Yun SC, Lee PH, et al. Randomized trial of stents versus bypass surgery for left main coronary artery disease: 5 year outcomes of the PRECOMBAT study. J Am Coll Cardiol. 2015;65: 2198-206.

9. Kim YH, Park DW, Ahn JM, Yun SC, Song HG, Lee JY, et al; PRECOMBAT-2 Investigators. Everolimus-eluting stent implantation for unprotected left main 
coronary artery stenosis: the PRECOMBAT-2 (Premier of Randomized Comparison of Bypass Surgery versus Angioplasty Using Sirolimus-Eluting Stent in Patients with Left Main Coronary Artery Disease) study. JACC Cardiovasc Interv. 2012;5:708-17.

10. Serruys PW, Morice MC, Kappetein AP, Colombo A, Holmes DR, Mack MJ, et al; SYNTAX Investigators. Percutaneous coronary intervention versus coronary-artery bypass grafting for severe coronary artery disease. $N$ Engl $J$ Med. 2009;360:961-72.
11. Morice MC, Serruys PW, Kappetein AP, Feldman TE, Ståhle E, Colombo A, et al. Five-year outcomes in patients with left main disease treated with either percutaneous coronary intervention or coronary artery bypass grafting in the Synergy between either percutaneous coronary intervention with taxus and cardiac surgery trial. Circulation. 2014;129:2388-94.

12. Lee R, Matsutani N, Polimenakos AC, Levers LC, Lee M, Johnson RG. Preoperative noncontrast chest computed tomography identifies potential aortic emboli. Ann Thorac Surg. 2007;84:38-41; discussion 42. 